Esta revista forma parte del acervo de la Biblioteca Jurídica Virtual del Instituto de Investigaciones Jurídicas de la UNAM

\title{
Instituto Nacional de Elecciones Entrevista a Luis Carlos Ugalde
}

¿Cuál es tu posición respecto a la propuesta de crear un Instituto Nacional de Elecciones?

Mi posición es en contra por dos razones principalmente:

1. Porque no contribuiría a solucionar los problemas centrales de la democracia electoral;

2. Porque podría hacer realidad el Principio de Peter aplicado al IFE: "Las organizaciones que realizan bien su trabajo son sobrecargadas de nuevas responsabilidades hasta alcanzar su nivel de incompetencia”, o dicho de forma más coloquial, para qué poner a prueba a una institución como el IFE que hace bien su trabajo operativo con más funciones que puede realizar mal.

Hay dos objetivos que enuncian quienes están a favor de centralizar la organización electoral:

1. Fortalecer la independencia e imparcialidad de las autoridades electorales locales. Y eso requiere, según los proponentes, combatir la intromisión de los gobernadores en los procesos electorales.

2. Reducir los costos de la organización de elecciones.

Hay que analizar si la creación de un instituto nacional es eficaz para atender ambos objetivos. Además de verificar que los pros de esta idea superen los contras. 


\section{¿Qué tan cierto es que las autoridades electorales locales han perdido autonomía frente a los gobernadores?}

Es cierto que hay un problema de intento de captura de autoridades electorales por parte de algunos gobernadores en algunas entidades. Pero la solución de fondo a este problema pasa por los equilibrios de poder en las entidades y por combatir el ejercicio meta constitucional del poder político. Ese es un gran problema, no sólo en materia electoral, sino uno de los grandes problemas de la democracia mexicana.

Si se lleva esta estrategia al extremo -la de centralizar funciones que no se realizan adecuadamente en las entidades- habría que considerar también nacionalizar los poderes legislativos porque algunos de ellos también son cooptados políticamente por los gobernadores, o incluso centralizar los órganos judiciales. La consecuencia lógica de estas acciones sería postergar el desarrollo político local, más que solucionar el problema de fondo. Es importante resaltar que la nacionalización de funciones políticas no es la ruta para estimular la rendición de cuentas de los gobiernos locales.

\section{¿Consideras que hay alternativas diferentes a la creación del INE para fortalecer la independencia de las autoridades electorales?}

Hay alternativas para combatir la intromisión de algunos gobernadores y autoridades locales, en lugar de "nacionalizar" la función electoral. Por mencionar algunas:

1. El primero es el desempeño profesional e independiente de los poderes legislativos. En este tema, la mesa central que se instaló al interior del Pacto por México para dar seguimiento a los procesos electorales locales de 2013 distorsionó el sistema de rendición de cuentas de los órganos electorales y distrajo la atención de este tema central para el fortalecimiento democrático.

2. La segunda, los mecanismos de nombramiento de las autoridades electorales. Es deseable considerar mecanismos de selección alternativos, para limitar la influencia de los gobernadores en la designación.

a) Crear un sistema de selección de dos fases: una en la que los partidos tengan la oportunidad de ponerse de acuerdo y otra aleatoria que se active cuando no exista consenso entre los partidos. 
b) La fase partidista se compone de: la selección de candidatos, que incluso puede ser de forma proporcional a su representación política en el Congreso. Es necesario crear un sistema transparente de inscripción, con requisitos claros y entrevistas a los candidatos.

c) A partir de la selección previa se elabora una lista de finalistas.

d) Para evitar el estancamiento cuando no exista consenso entre los partidos habría que considerar un sistema de voto transferible, o bien, elegir entre los candidatos finalistas mediante insaculación.

e) Si aun así no se lograra un nombramiento, la atribución pasaría al Tribunal Electoral para que resuelva la controversia.

3. En tercer lugar es importante reforzar el principio de inamovilidad de los consejeros locales para fortalecer su independencia.

4. Ampliar el periodo de ejercicio de los consejeros locales a plazos de siete años, ya que en 13 entidades el periodo de los consejeros es de entre tres o cuatro años, lo que mina su independencia de otros poderes.

5. Prohibir la reelección de los consejeros electorales, pues esto genera incentivos para que estos funcionarios busquen quedar bien con uno u otro partido a fin de mantenerse en su puesto para el siguiente periodo.

\section{¿Es real el argumento de que el INE ahorraría mucho dinero?}

La creación de un Instituto Nacional de Elecciones reduciría algunos costos de la organización electoral, pero el problema real del costo de la democracia no es ese, sino el del financiamiento líquido no registrado. El costo de los institutos y órganos electorales en 2012 fue de 6800 millones al año aproximadamente: 1109 millones se destinaron a los tribunales y 5661 millones a los institutos. Esta cifra dista mucho de ser un problema real para el presupuesto federal.

Si el objetivo de la reforma es ahorrar recursos derivados del costo del sistema electoral, valdría más la pena que considerara las siguientes fuentes de ahorro:

a) Combatir el costo creciente de las campañas electorales, o

b) Reducir las prerrogativas a los partidos políticos

Aun con un Instituto Nacional de Elecciones los problemas centrales de la democracia no se solventarán, hay problemas estructurales de nuestro sistema democrático que no necesariamente tienen su origen en los institutos electorales. Algunos de estos problemas son: 
a) Costo creciente de las campañas;

b) Clientelismo electoral (coacción e intento de compra del voto), y

c) Una ineficaz y creciente litigiosidad electoral.

Más allá de que la creación del INE no elimine los problemas fundamentales de la democracia mexicana, es importante meditar en los problemas operativos que tendría la implementación de este instrumento. No quedan claros los medios de los que se valdrá este Instituto para hacer frente a la organización de elecciones en todos los territorios del país, en cada distrito y para cada una de las elecciones que se tienen contempladas.

\section{¿Cuáles consideras que son los errores del debate sobre la posible reforma político-electoral?}

El primero error que identifico es poner el instrumento por delante de los objetivos, es decir, pensar primero en los mecanismos institucionales o legales que se quieren adicionar al sobrerregulado sistema electoral mexicano antes de tener claridad sobre los objetivos que se buscan alcanzar con dichos instrumentos. De esta forma se avanza sin tener una dirección clara.

El segundo error que detecto en la discusión pública es que no se parte de un diagnóstico de las fortalezas y debilidades del sistema electoral, por lo que adelanto que no se han identificado las principales causas de los problemas del sistema electoral. De suerte que las reflexiones se basan en propuestas que atienden un problema a la vez, muchas veces ni siquiera un problema sustancial de nuestro sistema electoral, en lugar de avanzar de forma comprensiva para mejorar el sistema en su conjunto. 